\title{
Protective effect of 4,4'-diaminodiphenylsulfone against paraquat-induced mouse lung injury
}

\author{
Sung Chun Cho', Ji Heon Rhim ${ }^{1}$, Hae Ri Choi ${ }^{1}$, \\ Young Hoon Son ${ }^{1}$, Seok Jin Lee, \\ Kye-Yong Song ${ }^{2}$ and Sang Chul Park ${ }^{1,3,4}$ \\ ${ }^{1}$ Department of Biochemistry and Molecular Biology \\ Institute on Aging \\ Seoul National University College of Medicine \\ Seoul 110-799, Korea \\ ${ }^{2}$ Department of Pathology \\ Chung-Ang University College of Medicine \\ Seoul 156-756, Korea \\ ${ }^{3}$ Lee Gil Ya Cancer and Diabetes Institute \\ Gachon University of Medicine and Science \\ Incheon 406-840, Korea \\ ${ }^{4}$ Corresponding author: Tel, 82-2-740-8255; \\ Fax, 82-2-740-4534; E-mail, scpark@snu.ac.kr \\ http://dx.doi.org/10.3858/emm.2011.43.9.060
}

Accepted 12 July 2011

Available Online 18 July 2011

\begin{abstract}
Abbreviations: DDS, 4,4'-diaminodiphenylsulfone; DHE, dihydroethidium; ET-1, endothelin-1; GR, glutathione reductase; GST $\pi$, glutathione S-transferase $\pi$; MDA, malondialdehyde; MIP- $1 \alpha$, macrophage inflammatory protein- $1 \alpha$; MMP-9, matrix metalloproteinase- 9 ; MnSOD, manganese superoxide dismutase; NAC, N-acetyl-I-cysteine; NOX, NADPH oxidase; $\mathrm{PKC}$, protein kinase $\mathrm{C}$; $\mathrm{PQ}$, paraquat; $\mathrm{Prdx1}$, peroxiredoxin 1; ROS, reactive oxygen species; TBARS, thiobarbituric acid reactive substances
\end{abstract}

\begin{abstract}
Although 4,4'-diaminodiphenylsulfone (DDS, dapsone) has been used to treat several dermatologic conditions, including Hansen disease, for the past several decades, its mode of action has remained a topic of debate. We recently reported that DDS treatment significantly extends the lifespan of the nematode $C$. elegans by decreasing the generation of reactive oxygen species. Additionally, in in vitro experiments using non-phagocytic human fibroblasts, we found that DDS effectively counteracted the toxicity of paraquat (PQ). In the present study, we extended our work to test the protective effect of DDS against $P Q$ in vivo using a mouse lung injury model. Oral administration of DDS to mice significantly attenuated the lung tissue damage caused by subsequent administration of $P Q$.
\end{abstract}

\begin{abstract}
Moreover, DDS reduced the local expression of mRNA transcripts encoding inflammation-related molecules, including endothelin-1 (ET-1), macrophage inflammatory protein-1 $\alpha$ (MIP-1 $\alpha$ ), and transforming growth factor- $\beta$ (TGF- $\beta$ ). In addition, DDS decreased the PQ-induced expression of NADPH oxidase mRNA and activation of protein kinase $C_{\mu}\left(\mathrm{PKC}_{\mu}\right)$. DDS treatment also decreased the $P Q$-induced generation of superoxide anions in mouse lung fibroblasts. Taken together, these data suggest the novel efficacy of DDS as an effective protective agent against oxidative stress-induced tissue damages.
\end{abstract}

Keywords: antioxidants; Dapsone; lung injury; mice; paraquat; reactive oxygen species; toxicity

\section{Introduction}

The anti-inflammatory compound 4,4'-diaminodiphenylsulfone (DDS, dapsone) has been used to treat many skin diseases, especially Hansen disease, for the last several decades (Wolf et al., 2002). Despite its long-term use, the issue of whether its mode of action as an antioxidant or pro-oxidant is a still ongoing debate (Niwa et al., 1984; Anderson et al., 1987; Bradshaw et al., 1997; Reilly et al., 1999). Recently, we observed and reported an interesting phenomenon that the lifespan of Hansen disease patients in Korea, most of whom have taken DDS for several decades, would be longer than that of the ordinary people despite their socioeconomic and medical disadvantages (summarized in Shimokawa et al. 2009).

Although the extended lifespan of Hansen disease patients might ensue from many possible factors, we have focused on the effect of their longterm treatment with DDS. Previously, DDS has been known to suppress ROS production in phagocytic neutrophils (Suda et al., 2005). In addition, we also showed that DDS effectively suppresses ROS generation in non-phagocytic cells by inhibiting the NADPH oxidase (NOX) system (Cho et al., 2010a). Furthermore, we could recently report that DDS treatment significantly extends the lifespan of the nematode C. elegans (Cho et al., 2010b). Therefore, in this study, we tried to confirm the antioxidant efficacy of DDS in an in vivo mouse model.

Paraquat is widely used as a potent herbicide and can cause severe toxicity in many organs 
(Tomita, 1991). Owing to its local accumulation, the lung is the primary site of the toxic effects of $P Q$. $P Q$-induced lung injury involves interstitial edema, alveolar hemorrhage, interstitial inflammation, and bronchial epithelial cell proliferation, ultimately resulting in fibrosis (Nerlich et al., 1984). Animal models of $P Q$-induced lung injury have been commonly used to investigate the pathogenesis of pulmonary fibrosis and to evaluate the therapeutic efficacy of agents. Here, we used a mouse model of PQ-induced lung injury to examine the effect of DDS in vivo on $\mathrm{PQ}$ toxicity.

Paraquat-induced pulmonary fibrosis results from the direct damage caused by oxygen free radicals as well as from the indirect injury caused by inflammatory cells and fibroblasts, with the involvement of several cytokines and growth factors (Cooper et al., 1988). The toxic drug-induced high expression of mRNA for monocyte chemoattractant protein-1 (MCP-1) and macrophage inflammatory protein-1 $\alpha$ (MIP-1 $\alpha$ ) is responsible for the pulmonary fibrosis in the lung tissues (Ishida et al., 2006). Transforming growth factor- $\beta$ (TGF- $\beta$ ), a potent fibrogenic growth factor, also promotes pulmonary fibrosis, by enhancing the transcription of collagen genes (Ishida et al., 2006). In addition, endothelin-1 (ET-1) has been reported to participate in the pathogenesis of bleomycin-induced and idiopathic pulmonary fibrosis (Kähler et al., 2000; Kaehler et al., 2002). Furthermore, lung ET-1 expression was shown to be upregulated during $P Q$-induced pulmonary fibrosis (Kim et al., 2006).

The production of ROS may also contribute to $P Q$-induced pulmonary fibrosis (Bus et al., 1976; Bonneh-Barkay et al., 2005). The principal mediator of $P Q$ toxicity has been suggested to be ROS, and $P Q$ has been widely used to trigger oxidative stress via generation of the superoxide anion, hydrogen peroxide, hydroxyl radicals, and in the presence of nitric oxide, peroxynitrite. Superoxide anions are generated by $\mathrm{PQ}$ via NADPH-dependent metabolic pathways (Bonneh-Barkay et al., 2005) and via mitochondria (Castello et al., 2007). Notably, NADPH oxidases, NOX2 and NOX4, are predominantly expressed in lung tissues (van der Vliet, 2008; Hecker et al., 2009). Moreover, protein kinase $C$ (PKC) participates in the ligand-initiated assembly of NOX, which proceeds the generation of superoxide anions (Miller et al., 2007). Among more than 20 different PKC isoforms present in mammalian cells, several PKC isoforms are already reported to be linked with expression or activation of NOX; such as PKC $\mu$ in lung (Rennecke et al., 1996), PKC $\delta$ in mouse adipocytes (Talior et al., 2005) and microglial cells (Miller et al., 2007), and PKC $\alpha$ in human endothelial cells (Xu et al.,
2008). Since several PKC isoforms, including PKC $\alpha, \beta, \delta$, and $\mu$, are expressed in lung, it is necessary to confirm the possible involvement of a specific $P K C$ isoform that is associated with $P Q$-induced ROS generation in the mouse lung.

Since the oxidative damage is one of the major contributors to the toxic effects of $P Q$, the use of antioxidants to treat $P Q$ poisoning appears to be an effective and feasible option for preventing or treating the consequent damage. In fact, the administration of the antioxidant $\mathrm{N}$-acetyl-I-cysteine (NAC) before $P Q$ treatment has been shown to attenuate $P Q$ toxicity (Hoffer et al., 1993). In this study, we tested the efficacy of DDS as an effective antioxidant against toxicant-induced oxidative stress in vivo using a mouse $P Q$-induced lung injury model.

\section{Results}

\section{DDS attenuates the PQ-induced pulmonary damage}

Control (saline-treated) mice displayed normal pulmonary structure, as assessed by examining $\mathrm{H} \& E$-stained lung tissue sections. The lungs of animals treated for 5 days with $P Q(10 \mathrm{mg} / \mathrm{kg})$ appeared abnormal, but no mice in any treatment group died. Histopathological examination of the lungs of PQ-treated mice revealed major differences compared with controls. On day 5 after exposure to $P Q(10 \mathrm{mg} / \mathrm{kg})$, the lungs exhibited pulmonary edema, inflammatory cell recruitment, hemorrhage, and light fibrosis. These abnormalities, particularly inflammation and hemorrhage, were dramatically attenuated in animals pretreated with DDS (PQ + DDS group; DDS, 0.5 or $2 \mathrm{mg} / \mathrm{kg}$ ). As expected, animals treated with DDS alone (2 $\mathrm{mg} / \mathrm{kg}$ ) had a normal pulmonary structure. As a positive control, NAC-treated mice were protected against the deleterious effects of $P Q(P Q+N A C$ group) (Figure 1). These data indicate that DDS is effective for preventing $P Q$-induced lung tissue damage in mice.

\section{DDS itself cannot inhibit $P Q$ uptake}

When $P Q$ was administered to the mouse via i.p. injection, a significant amount of $P Q$ was detected in the lung tissue using HPLC analysis. However, this uptake of $P Q$ was not significantly inhibited by oral pretreatment of DDS (Figure 2). Since DDS could not affect the $P Q$ uptake by lung tissue, we paid our attention on the mechanism how it attenuated the $P Q$-induced pulmonary damage. 

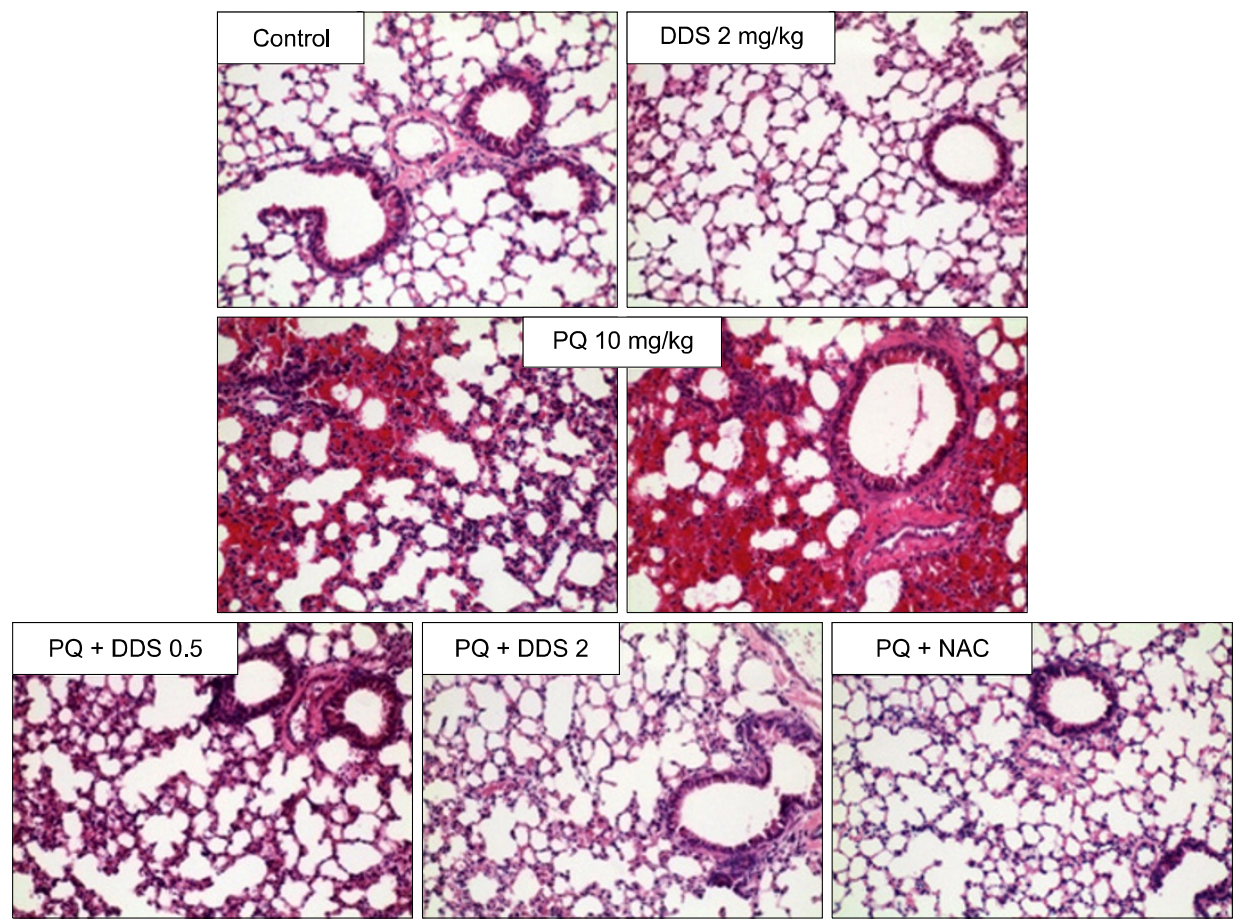

Figure 1. Effect of DDS on $P Q$-induced pulmonary fibrosis. Histological evaluation of lungs from saline-injected (control) mice; mice treated with $2 \mathrm{mg} / \mathrm{kg}$ (human therapeutic dose) DDS alone; mice treated once with $10 \mathrm{mg} / \mathrm{kg} P Q$; mice treated with $P Q$ and 0.5 or $2 \mathrm{mg} / \mathrm{kg}$ DDS; and mice treated with NAC $(3 \times 100 \mathrm{mg} / \mathrm{kg})$ following exposure to $P Q$. The lungs were removed, fixed in $4 \%$ formaldehyde, and embedded in paraffin. Tissue sections were cut and stained with hematoxylin and eosin. Histopathological images are presented as light micrographs $(200 \times$ magnification).

\section{DDS decreases the PQ-induced expression of inflammatory cytokines}

Inflammation contributes to $P Q$-induced pulmonary damage, and several factors, including cytokines, chemokines, and growth factors, may contribute to the pathogenesis of pulmonary fibrosis (Smith et al., 1995; Martinet et al., 1996). It has been reported that the expression of ET-1 and MIP- $1 \alpha$ was significantly increased in the mouse lung within 5
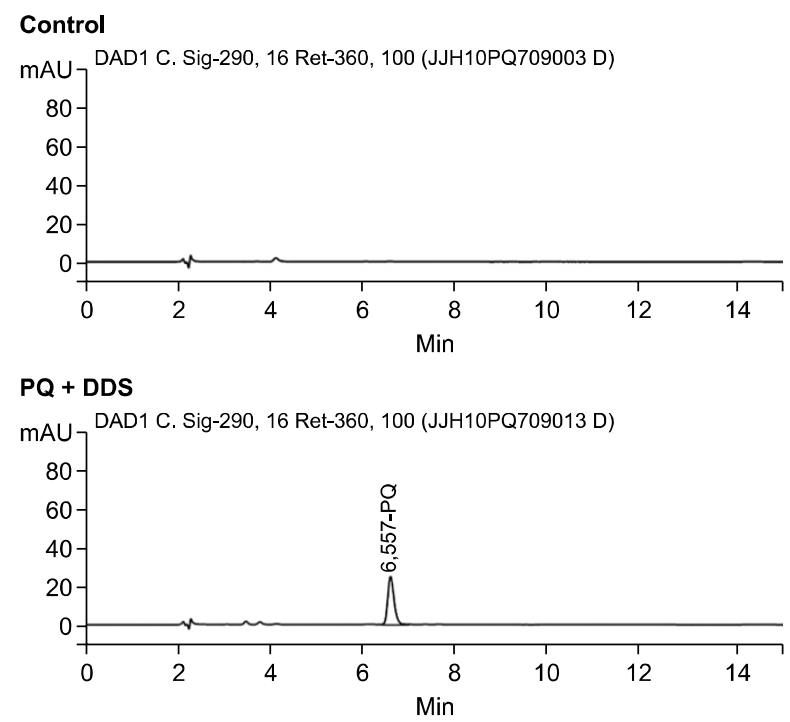

days of exposure to $P Q$ (Ishida et al., 2006). To analyze the effects of DDS on PQ-induced inflammation and lung damage, the mRNA expression of key genes in the lungs of $P Q$-treated mice was examined by RT-PCR. The mRNA levels of both ET-1 and MIP-1 $\alpha$ were increased significantly in $P Q$-treated mice (Figures 3A-3C). The mRNA levels of tumor necrosis factor- $\alpha$ (TNF- $\alpha$ ) and TGF- $\beta$ were previously reported to be significantly in-
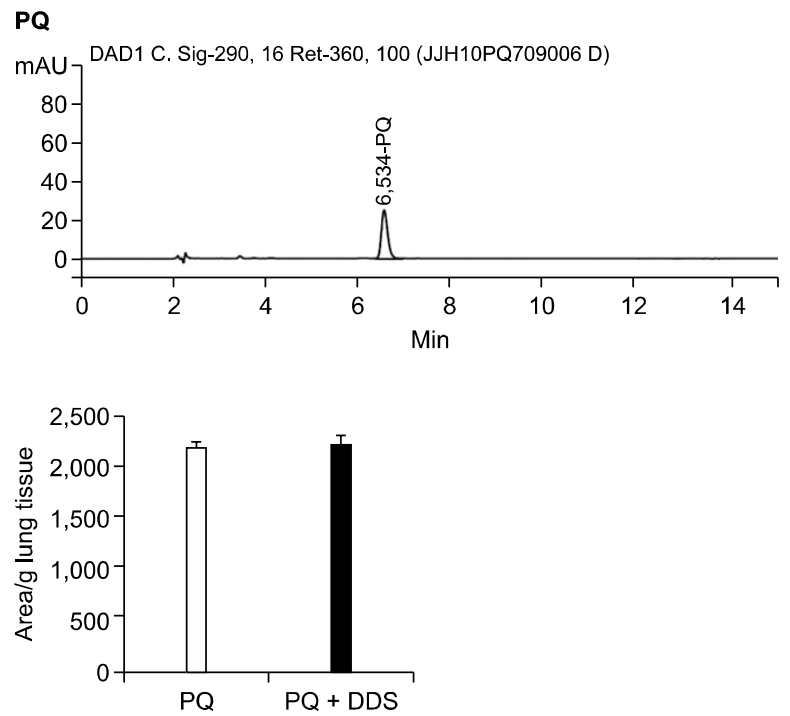

Figure 2. Effect of $D D S$ on $P Q$ uptake in mouse lung tissues. The level of $P Q$ uptake was examined in lung tissues from mice treated with saline (control), $\mathrm{PQ}$ alone, and $\mathrm{PQ}+\mathrm{DDS}(2 \mathrm{mg} / \mathrm{kg}, n=3)$ using HPLC analysis. HPLC samples were prepared and analyzed as described in Methods. 
A

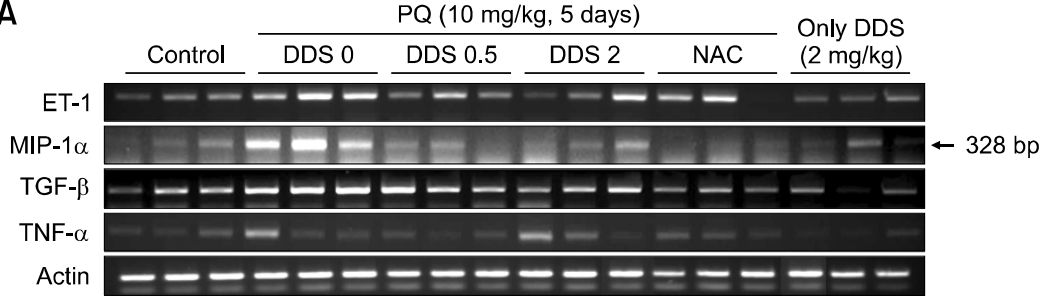

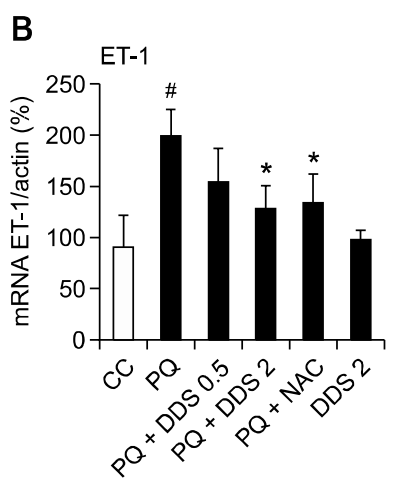

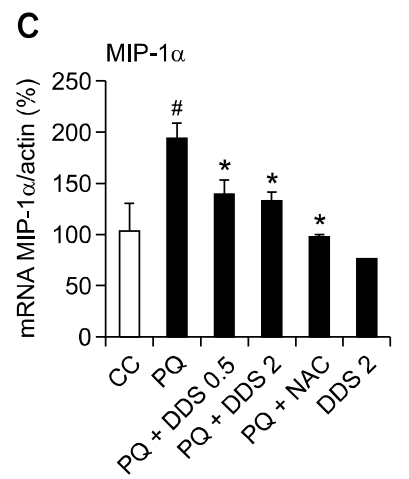

creased within 2-3 weeks after $P Q$ treatment (Ishida et al., 2006). In the present study, the expression of TGF- $\beta$, but not TNF- $\alpha$, mRNA was increased significantly after $P Q$ treatment (Figures $3 A$ and $3 D$ ). These changes in mRNA expression were attenuated by pretreatment with DDS, as well as by NAC treatment after PQ exposure. No significant differences in mRNA expression were detected between mice treated with DDS alone and saline-treated controls. These data implicate that regulation of several key inflammatory factors could be involved in the protective effect of DDS against $P Q$-induced mouse lung damage.

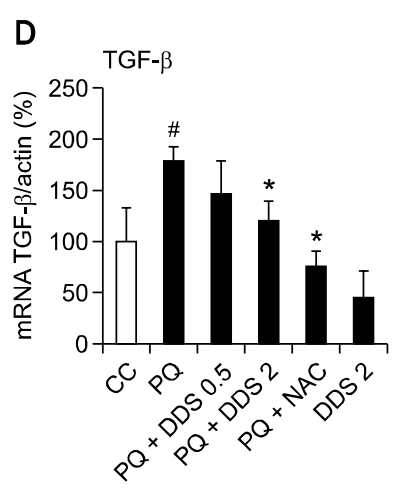

Figure 3. RT-PCR analysis of ET-1, MIP- $1 \alpha$, TNF- $\alpha$, and TGF- $\beta$ mRNA levels in lung tissues from $P Q$-treated mice. Total mouse lung RNA was prepared and analyzed by RT-PCR using primers specific for ET-1, MIP- $1 \alpha$, TNF- $\alpha$, and TGF- $\beta$ mRNA. PCR products were separated by electrophoresis in $1.2 \%$ agarose gels $(A)$, with $\beta$-actin as a loading control. Quantified data $(n=3)$ are presented in bar graphs $(B, C, D)$. ${ }^{\#} P<0.005$ vs. control mice (CC); ${ }^{*} P<0.005$ vs. $P Q$-treated mice $(P Q)$.

\section{DDS controls the PQ-induced mRNA expression of NOX4}

Increased expression of ET-1 in PQ-induced pulmonary fibrosis may result from oxidative stress, as well as inflammation, as $P Q$ is known to trigger oxidative stress (Kähler et al., 2000; Kaehler et al., 2002). Therefore, the ability of DDS to reduce oxidative stress and thereby protect against $P Q$-induced mouse lung damage has been tested. As $P Q$ treatment results in increased expression of NOX (Rossary et al., 2007; Cho et al., 2010a), which generates superoxide anions, we examined the expression of NOX2 and NOX 4 mRNA in the lung tissues. The expression of NOX4 mRNA was
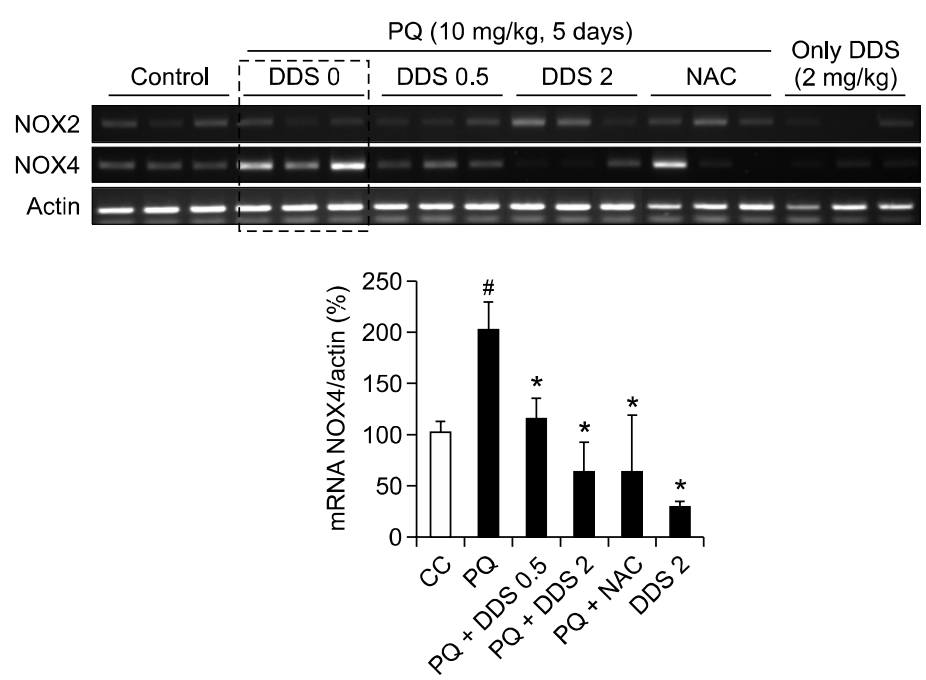

Figure 4. Effect of DDS on PQ-induced NADPH oxidase 4 mRNA expression in mouse lung tissue. Total mouse lung RNA was prepared and analyzed by RT-PCR using primers specific for NOX2 and NOX4 mRNA. Target gene expression levels were normalized to the $\beta$-actin signal. Quantified data $(n=3)$ are presented in bar graphs (lower panel). ${ }^{\#} P<0.005$ vs. control mice (CC); ${ }^{*} P$ $<0.005$ vs. $P Q$-treated mice $(P Q)$. 


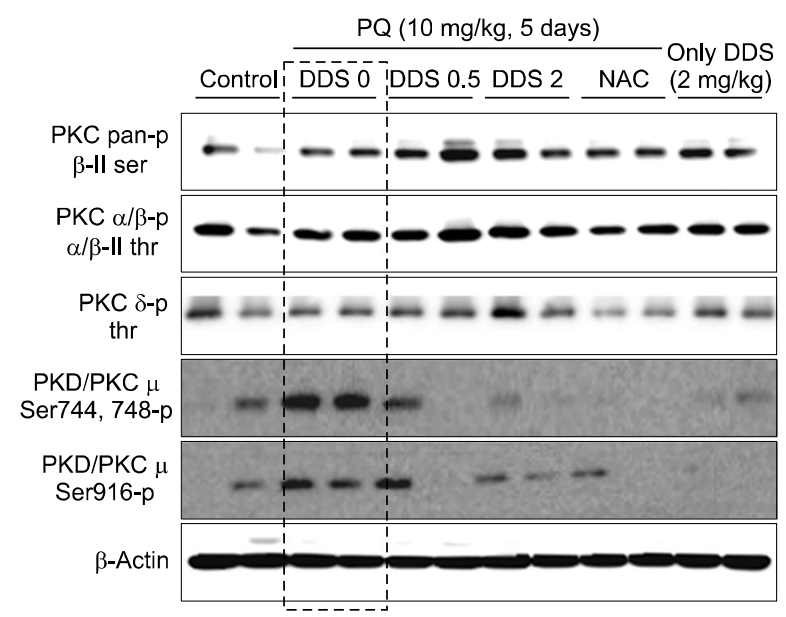

Figure 5. Effect of DDS on $P Q$-induced $P K C$ activation in mouse lung tissue. $P Q$-induced PKC phosphorylation was evaluated by Western blotting. Mice were pretreated daily with oral DDS (0.5 or $2 \mathrm{mg} / \mathrm{kg}$ ) for 1 week and then treated once with $10 \mathrm{mg} / \mathrm{kg} \mathrm{PQ}$. The lungs were removed and homogenized in lysis buffer. PKC phosphorylation was determined using antibodies against PCKpan-p, PCK $\alpha / \beta-p$, PKC $\delta-p$, and PKC $\mu-p$. Immunoreactive protein bands were visualized by $\mathrm{ECL}$ and exposure to autoradiographic film.

increased significantly in mice exposed to $P Q$ (Figure 4), and this induction was suppressed by pretreatment with DDS. However, any significant change in NOX2 mRNA expression by $P Q$ treatment or DDS was not observed.

\section{DDS inhibits $P Q$-induced $P K C \mu$ activation and superoxide anion generation in vitro and in vivo}

PKC isoforms have been implicated in the generation of superoxide anions via NOX activation (Miller et al., 2007). Western blot analysis with antiphospho-PKC antibodies was carried out to examine the phosphorylation status of specific PKC isoforms in mouse lung after $P Q$ treatment. $P Q$ induced the phosphorylation of $\mathrm{PKC} \mu$ at Ser744/748 and Ser916 (Figure 5), whereas the phosphorylation of the other PKC isoforms, including $P K C \alpha$, $\beta$, and $\delta$, was not altered by $P Q$ treatment. In addition, the basal levels of lung PKCs were not changed (data not shown). PQ-induced phosphorylation of $\mathrm{PKC}_{\mu}$ in mouse lung tissue was inhibited by DDS. Therefore, DDS can suppress $P Q$-induced PKC activation and the subsequent induction of NOX4 in vivo.

Given the limitations to monitoring ROS generation in tissues, we measured $P Q$-induced superoxide anion generation in a cellular model. Previously, we reported that DDS inhibited PQ-induced superoxide anion generation in non-phagocytic human diploid fibroblasts by inhibiting the activation of PKC, especially the $\beta$ isoform. DDS was tested at concentrations of 1 and $20 \mu \mathrm{M}$, the range of plasma DDS concentrations in patients treated with DDS, and these concentrations appear to be safe and effective for long-term use (Zuidema et al., 1986). Because in vivo experiment showed that $\mathrm{PKC} \mu$ was strongly affected by $P Q$ treatment in the mouse lung tissues, we examined the phosphorylation status of $\mathrm{PKC} \mu$ in vitro in primary mouse lung fibroblasts in response to $P Q$ treatment. Western blot analysis revealed that $P Q$ treatment enhanced the phosphorylation of $\mathrm{PKC} \mu$ at Ser744/ 748 and Ser916 in lung fibroblasts at 3, 5, 10, 15, and $30 \mathrm{~min}$ with peak induction at $5 \mathrm{~min}$, similar to that observed in mouse lung tissues and that PQinduced phosphorylation of $\mathrm{PKC} \mu$ was inhibited by DDS (Figures 6A and 6B) dose dependently, as well as by Gö6983, a well-known inhibitor of $P K C \mu$.

Based on the DHE assay results using fluorescence microscopy, $P Q$ induced the generation of superoxide anion, which was decreased by DDS, presumably by inhibiting $\mathrm{PKC} \mu$ activation (Figure 6C). These data suggest that DDS protects against the toxic effects of $P Q$ by inhibition of $P Q$-induced $P K C \mu$ activation and the consequent reduction in superoxide anion generation not only in vitro, but also in vivo.

Based on the direct DHE assay, using HPLC, it was confirmed that DDS could reduce the superoxide anion generation by $P Q$. Figure $6 D$ shows the HPLC profiles of intracellular levels of 2-OH$\mathrm{Et}^{+}$(peak 1) and $\mathrm{Et}^{+}$(peak 2) after the respective treatment, indicating that $\mathrm{PQ}$ stimulated $2-\mathrm{OH}-\mathrm{Et}^{+}$ in mouse lung fibroblasts, which was blocked by DDS. As a positive control, we used Gö6983, a well-known inhibitor of $\mathrm{PKC} \mu$, which resulted in reduction of superoxide anion generation (Figures $6 \mathrm{C}$ and $6 \mathrm{D}$ ). These data implicated that the protective role of DDS against the toxic effects of $P Q$ would be related with inhibition of $P Q$-induced $P K C \mu$ activation and the consequent reduction in superoxide anion generation not only in vitro, but also in vivo.

\section{DDS reduces $P Q$-induced lipid peroxidation in mouse lung tissues}

To measure the oxidative stress caused by $P Q$-induced superoxide anions, we monitored lipid peroxidation by quantifying the levels of TBARS in the lungs of $P Q$-treated mice. $P Q$ treatment significantly enhanced lipid peroxidation in mouse lung tissues (Figure 7), and treatment with DDS or NAC significantly suppressed the $P Q$-induced lipid peroxidation. These data suggest that DDS might be effective in preventing oxidative damage in 
A

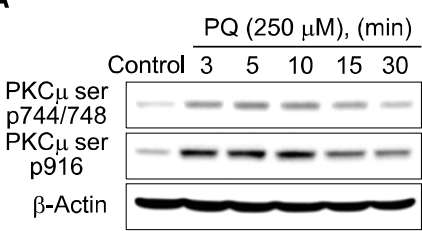

C

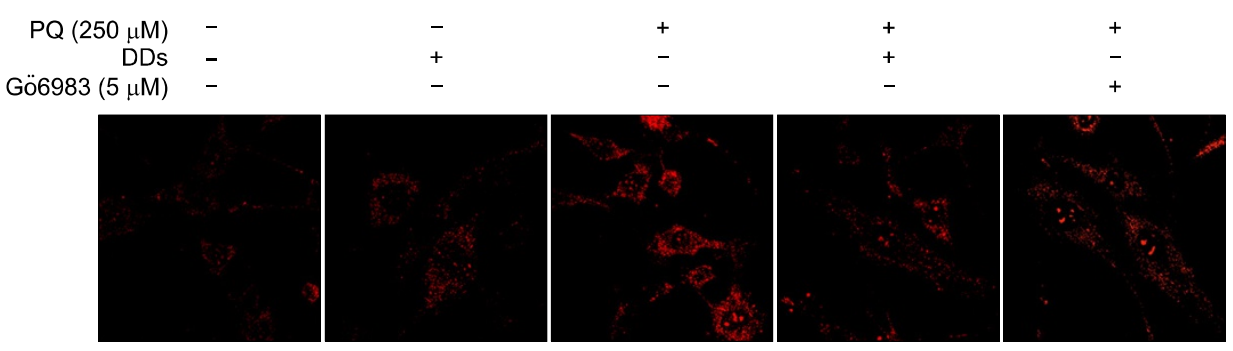

D

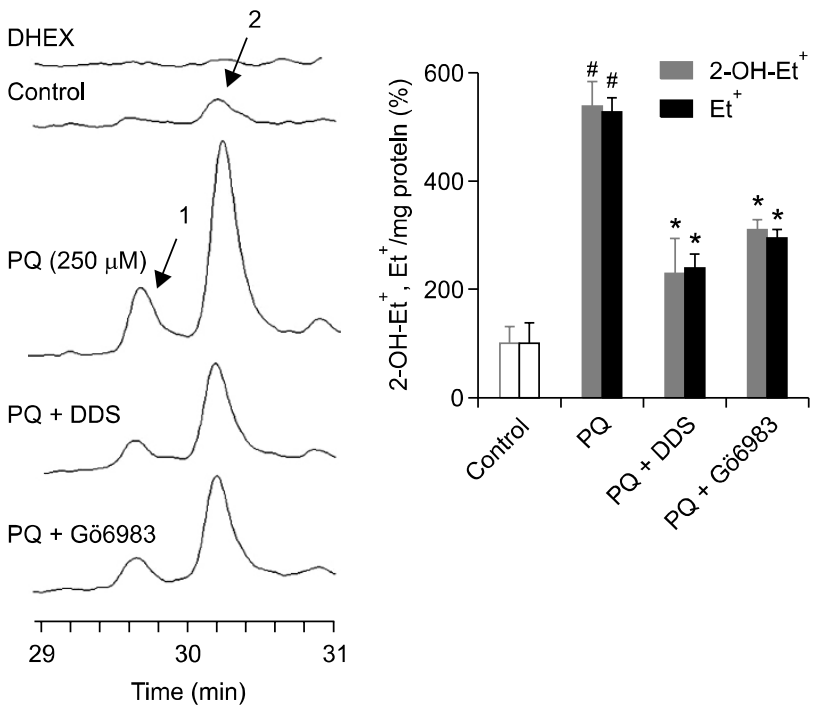

Figure 6. Effect of DDS on $P Q$-induced PKC activation and superoxide anion generation in primary mouse lung fibroblasts. (A) Primary mouse lung fibroblasts were exposed to $250 \mu \mathrm{M} P Q$ at $3,5,10,15$, and $30 \mathrm{~min}$, and then the phosphorylation of PKC $\mu$ at Ser744/748 and Ser916 was determined using Western blot analysis. (B) Primary mouse lung fibroblasts were pretreated with DDS $(0.1,1,5$, or 20 $\mu \mathrm{M})$ for $3 \mathrm{~h}$ or with $5 \mu \mathrm{M}$ Gö6983 for 30 min. After treatment with $250 \mu \mathrm{M}$ $P Q$ for 5 min, cells were lysed. Proteins were analyzed by Western blotting using antibodies against phosphorylated PKC $\mu$. $\beta$-Actin was used as loading control. (C) Intracellular superoxide anion levels were measured by dihydroethidium (DHE) assay using fluorescence microscopy. After treatment with $250 \mu \mathrm{M}$ $P Q$ for 30 min, cells were incubated with $5 \mu \mathrm{M}$ DHE for $15 \mathrm{~min}$ at $37^{\circ} \mathrm{C}$ in the dark, and fluorescence was observed under an LSM 510 META fluorescence microscope. (D) HPLC analysis of superoxide anion production. HPLC samples were prepared and analyzed as described in Methods. The levels of $2-\mathrm{OH}-\mathrm{Et}^{+}$ (peak 1) and $\mathrm{Et}^{+}$(peak 2) were expressed as HPLC peak area per $\mathrm{mg}$ protein. The 2-OH-Et ${ }^{+}$and $\mathrm{Et}^{+}$generation data graphed is representative of three independent experiments. ${ }^{\#} P<0.05$ relative to control; ${ }^{*} P<$ 0.05 relative to $P Q$.

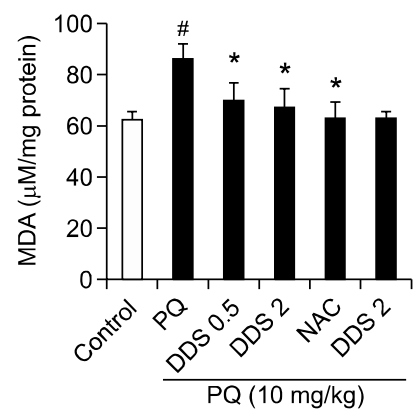

Figure 7. Effect of DDS on MDA levels in lung tissues from $P Q$-treated mice. TBARS assay was performed in lung tissues from mice treated with $P Q$ and DDS. MDA was measured as an index of lipid peroxidation in mice treated with saline (control), $P Q$ alone, $P Q+D D S, P Q+N A C$, or DDS alone $(n=6) .{ }^{\#} P<0.005$ vs. control mice (Control); ${ }^{*} P<$ 0.005 vs. PQ-treated mice (PQ).
PQ-treated mouse lung tissues.

\section{Pretreatment with DDS modulates the levels of oxidative damage-associated enzymes in mouse lung tissues}

Changes in the expression levels of several genes in the lungs of $P Q$-exposed mice have been reported (Satomi et al., 2004; Tomita et al., 2007). We examined the levels of lung injury-related enzymes 5 days post-PQ treatment with or without DDS pretreatment. The level of matrix metalloproteinase 9 (MMP-9) was increased 5 days after $P Q$ treatment, which was decreased by DDS pretreatment (Figure 8A). By contrast, the protein levels of MnSOD, GR, Prdx1, and GST $\pi$ were de- 
A

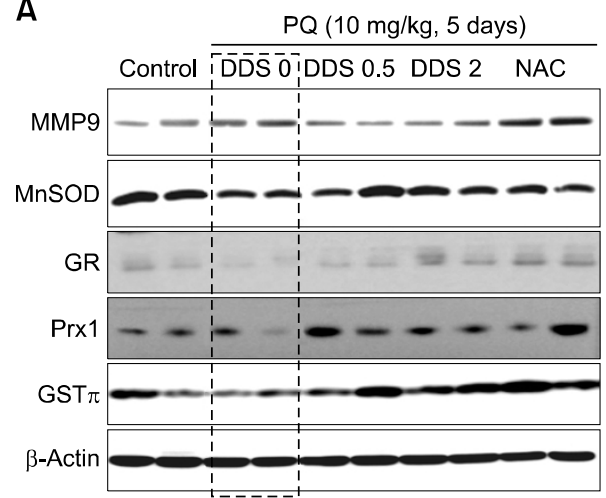

B

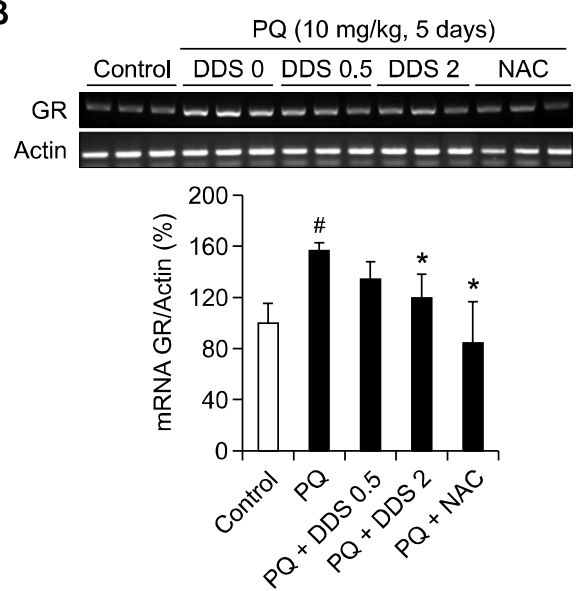

Figure 8. Effect of DDS on PQ-induced changes in oxidative damage associated enzymes. (A) The levels of several proteins in lungs from $P Q$ - and DDS-treated mice were evaluated by Western blotting. Lung tissues were removed and homogenized in lysis buffer. $P Q$ treatment increased the protein level of MMP-9 and decreased the protein levels of MnSOD, GR, Prdx1, and GST $\pi$. DDS reduced the effects of PQ on the protein levels. $\beta$-Actin was used as loading control. Protein bands were visualized by ECL. (B) Total mouse lung RNA was prepared and analyzed by RT-PCR using primers specific for GR mRNA. The PCR products were separated by electrophoresis in $1.2 \%$ agarose gels, with $\beta$-actin as a loading control. Quantified data $(n=3)$ are presented in bar graphs. ${ }^{\sharp} P<0.05$ vs. control mice (Control); ${ }^{*} P<0.05$ vs. PQ-treated mice (PQ).

creased in mouse lung tissues following $P Q$ treatment, which were prevented by DDS pretreatment (Figure 8A). Interestingly, the level of GR mRNA was increased after $P Q$ treatment as previously reported (Satomi et al., 2004), which was inhibited by DDS pretreatment (Figure 8B). However, the protein level of GR by Western blot analysis indicated the higher level of GR by DDS treatment and lower level by $P Q$ treatment, suggesting the role of DDS in enzymatic stability at the protein level, which needs further study. These data imply that the protective effect of DDS against $P Q$-induced damage in mouse lung tissues is achieved by modulating the levels of enzymes associated with oxidative damages, which were affected by $P Q$ treatment.

\section{Discussion}

Long-term treatment of Hansen disease with DDS at a standard dose (2 $\mathrm{mg} / \mathrm{kg}$ body weight per day) is associated with few clinically significant side effects (Zone, 1991). Although the primary side effect of DDS is anemia, we recently observed that hemoglobin levels in patients with Hansen disease, most of whom had taken DDS for decades, did not differ significantly from those in the control group, suggesting that DDS therapy would not be life-threatening in humans (Cho et al., 2010b).

Despite the therapeutic effects of DDS, its efficacy as an antioxidant or pro-oxidant is still debated. Several studies have shown that DDS can cause oxidative stress, particularly when used at high concentrations (Bhaiya et al., 2006; Veggi et al., 2008). Treatment of human dermal fibroblasts with high-concentration (1.5 mM) DDS (or one of its metabolites) induces oxidative stress and glutathione depletion (Bhaiya et al., 2006), and highconcentration DDS administration to rats $(30 \mathrm{mg} / \mathrm{kg})$ produces oxidative stress in the liver (Veggi et al., 2008). In contrast, dermatological application of $5 \%$ DDS gels have been reported to be safe and effective for long-term use (Piette et al., 2008), and patients with Hansen disease who have been undergoing long-term DDS therapy at a standard dose (100 mg per day) exhibit increased antioxidant activity in their blood (Cho et al., 2010b). Furthermore, we recently found that the mean and maximum lifespan of DDS-treated C. elegans worms are significantly greater than those of untreated worms (Cho et al., 2010b). The DDS-treated worms exhibited a decreased ROS-induction response to $P Q$ treatment and were less sensitive to $P Q$ (Cho et al., 2010b). In the same study, we confirmed that DDS has an antioxidant effect in PQ-treated human dermal fibroblasts, in which it effectively suppresses ROS generation by inhibiting the NOX system (Cho et al., 2010a).

Paraquat causes severe lung injury and elicits several changes in gene expression in the lung (Ishida et al., 2006; Tomita et al., 2007), during the destructive phase (i.e., 5 days post-exposure to $P Q$ ) that precedes the development of fibrosis. Cytokines, chemokines, and growth factors may contribute to the pathogenesis of pulmonary fibrosis (Smith et al., 1995; Martinet et al., 1996). Semi-quantitative 
RT-PCR analysis previously demonstrated that TNF- $\alpha$ and MCP-1 mRNA expression was significantly increased after exposure to $P Q$, compared with those in untreated controls (Ishida et al., 2006). Moreover, PQ-treated mice showed increased mRNA expression of fibrogenic growth factors, such as TGF- $\beta$, platelet-derived growth factor $A$, acidic fibroblast growth factor, and hepatocyte growth factor. In addition, the expression of MIP-1 $\alpha$, which is chemotactic for monocytes/macrophages, was also induced after $P Q$ treatment (Ishida et al., 2006). In the present study, the experiment lasted 5 days after exposure to $P Q$, at which time the lung TNF- $\alpha$ mRNA level was not significantly altered. However, TGF- $\beta$ mRNA expression was significantly enhanced in the mouse lung at 5 days after $P Q$ treatment. Consistent with previous findings, MIP- $1 \alpha$ mRNA expression was also significantly enhanced 5 days after $P Q$ treatment. As evidence of the importance of ET-1 in the pathogenesis of pulmonary fibrosis, transgenic mice overexpressing ET-1 in the lungs were shown to exhibit progressive development of pulmonary fibrosis (Hocher et al., 2000), and ET-1 mRNA expression was increased in the lungs of mice with $P Q$-induced pulmonary fibrosis. The induction of ET-1 expression may result from oxidative stress or the effects of proinflammatory cytokines associated with oxidative stress. In this study, we demonstrated that DDS treatment effectively suppressed the $P Q$-induced gene expression of MIP- $1 \alpha$, ET-1, and TGF- $\beta$ (Figure 3), which would result in attenuation of the $P Q$-induced damages, including pulmonary fibrosis.

Paraquat has been widely used to trigger oxidative stress via superoxide anion generation (Autor, 1974; Skillrud and Martin, 1984). Superoxide anions are a source of more toxic ROS such as hydroxyl radicals, which can cause extensive damages to DNA, proteins, and lipids. Many known antioxidant compounds exert their effects by scavenging ROS. However, we previously reported that DDS would not directly scavenge DPPH radicals in vitro, suggesting that DDS might exert its effects through regulation of ROS generation (Cho et al., 2010a). Paraquat induces superoxide anion production via NADPH-dependent metabolic pathways. NOX2 and NOX4 are the predominant NOX isoforms in the mouse lung (van der Vliet, 2008; Hecker et al., 2009), and NOX4 expression in pulmonary fibroblasts is selectively upregulated in response to inflammatory mediators such as TNF- $\alpha$ and TGF- $\beta$, subsequently increasing ROS production (Thabut et al., 2002; Sturrock et al., 2006; van der Vliet, 2008). In the present study, we found that DDS effectively inhibits the $P Q$-stimulated induction of
NOX4 expression, but not of NOX2 expression, in mouse lung tissues (Figure 4). Moreover, in our previous $C$. elegans study, we found that DDS treatment down-regulated transcription of the ceDuox1, a C. elegans NOX (Cho et al., 2010b). Unlike other NOX isoforms, NOX4 does not require cytosolic regulatory subunits such as p47phox/ p67phox or NOXO1/NOXA1 (Brandes et al., 2005) and GTPase Rac for activity control (Martyn et al., 2006). Rather, NOX4-mediated ROS generation was directly correlated with NOX4 expression (Serrander et al., 2007). Therefore, it can be summarized that PKCs can modulate ROS generation through regulation of NOX gene expression (Xu et al., 2008). However, it is not clear yet how PKC activation regulates NOX gene expression.

Previously, we reported that DDS could control PKC $\beta$ activity in human diploid fibroblasts (Cho et al., 2010a). In addition, our present study showed that DDS could effectively inhibit $P Q$-induced $\mathrm{PKC}_{\mu}$ activation in lung tissues and lung fibroblasts (Figures 5 and 6 ). PKC $\mu$ differs from other members of the PKC family in terms of its structural and enzymatic properties, and is ubiquitously expressed with the highest expression in the thymus, lung, and peripheral blood mononuclear cells (Rennecke et al., 1996; Tsunobuchi et al., 2004). Inhibition of $\mathrm{PKC}_{\mu}$ by its specific inhibitor, Gö6983, resulted in a decrease in its phosphorylation, which led to a reduction in intracellular superoxide generation (Figure 6). DDS had a similar effect as the $P K C \mu$ inhibitor on the $P Q$-induced changes.

Oxidative stress by $P Q$-induced superoxide anion generation results in lipid peroxidation in several model systems, which alters the structure and function of cellular membranes and blocks cellular metabolism (Tsukamoto et al., 2000; Venkatesan, 2000). Lipid peroxidation has been investigated in pulmonary diseases, including asthma, chronic obstructive pulmonary disease, cystic fibrosis, acute respiratory distress syndrome, and respiratory failure (Wood et al., 2005). In this study, we observed that DDS effectively reduced the $P Q$-induced production of MDA, the typical product of lipid peroxide (Figure 7). Given that antioxidants prevent ROS generation or scavenge ROS, the availability of safe, effective antioxidants should contribute greatly to preventing a wide range of oxidative stress-associated pathologies.

In addition, we examined the effect of DDS on the levels of key enzymes related to oxidative damage in the lung 5 days after $P Q$ treatment (Figure $8)$. The protein level of MMP-9, which influences the accumulation of collagen in fibrosis, was increased during the initial destructive phase of the response to PQ (Satomi et al., 2004). DDS effec- 
tively counteracted the $P Q$-induced upregulation of MMP-9. Furthermore, the lungs of $P Q$-treated mice showed significant down regulation of MnSOD and Prdx1. $P Q$ also resulted in decreased expression of the antioxidant GST $\pi$ in this study. This observation is consistent with a previous study in which a compound known to generate ROS significantly reduced GST activity (Du et al., 2004). The level of GR mRNA increased after PQ treatment as previously reported (Satomi et al., 2004), which was inhibited by DDS pretreatment (Figure 8B). However, unlike GR mRNA, the level of GR protein was decreased in $P Q$-treated mice in this study, but DDS treatment increased the level of GR protein, analyzed by Western blot analysis (Figure $8 \mathrm{~A})$. These data implicate the possible role of DDS in protein stability, which warrants further study. In addition, DDS showed an effective counteractive role in restoring the levels of antioxidative enzymes. These changes in protein levels of antioxidative enzymes by DDS might warrant further investigations to elucidate the mechanism of $P Q$-induced pulmonary damage and the protective effects of DDS.

This work showed that DDS effectively counteracts $P Q$-induced lung damage by modulating expression of inflammatory cytokines and NOX4, activation of PKC, formation of malondialdehyde, and the levels of antioxidative enzymes, in parallel with the pathological changes. Moreover, the long-term use of DDS by Hansen's patients for several decades without serious side effects supports its value as a reliable antioxidant for preventing many degenerative changes related to oxidative damage. Taken together, these findings lead us to conclude that DDS would be an effective antioxidant for preventing ROS generation and the subsequent damages, not only in the lungs, but also in many other relevant disorders.

\section{Methods}

\section{Reagents}

DDS was obtained from Taekeuk Pharmaceuticals (Seoul, Korea). $\mathrm{PQ}$ and NAC were purchased from Sigma-Aldrich Chemical Co. (St. Louis, MO). Trizol reagent was obtained from MRC (Cincinnati, OH); Gö6983, from Calbiochem (San Diego, CA); Sep-Pak $\mathrm{C}_{18}$ cartridge, from Waters Co. (Massachusetts, Ireland); and dihydroethidium (DHE), from Molecular Probes (Eugene, OR). A monoclonal antibody against $\beta$-actin was purchased from Sigma; polyclonal antibody against MMP-9, from Santa Cruz Biotechnology Inc. (Santa Cruz, CA); polyclonal antibodies against manganese superoxide dismutase (MnSOD), glutathione reductase (GR), and peroxiredoxin 1 (Prdx1), from AbFrontier (Seoul,
Korea); and polyclonal antibodies against PCKpan-p ( $\beta I I$ Ser660), PCK $\alpha / \beta-p$ (Thr638/641), PKC $\delta-p$, and PKC $\mu-p$ (Ser744/748 and Ser916) (phospho-PKC antibody sampler kit), from Cell Signaling Technologies, Inc. (Danvers, MA). An anti-glutathione S-transferase $\pi(\mathrm{GST} \pi)$ antibody was prepared in our laboratory. All other biochemical reagents were from Sigma.

\section{Animals, experimental conditions, and PQ administration}

Male BALB/c mice (20-25 g body weight, 4 weeks old), bedding, and food were purchased from Chung-Ang Laboratory Animal (Seoul, Korea). Animals were acclimatized for 1 week before use. The temperature was maintained at $21 \pm 1^{\circ} \mathrm{C}$ and the humidity at $60-70 \%$. Food and water were provided ad libitum. Mice were housed in plastic cages and subjected to a $12 \mathrm{~h}-12 \mathrm{~h}$ light-dark photocycle. The following treatments were applied: (1) control: intraperitoneal (i.p.) injection of saline; (2) $P Q$ : i.p. injection of $10 \mathrm{mg} / \mathrm{kg} \mathrm{PQ;} \mathrm{(3)} \mathrm{PQ} \mathrm{+} \mathrm{NAC:} \mathrm{single} \mathrm{i.p.} \mathrm{injection}$ of $10 \mathrm{mg} / \mathrm{kg} \mathrm{PQ}$, followed by i.p. injection of NAC (100 $\mathrm{mg} / \mathrm{kg}) 1,2$, and 4 days after exposure to $P Q$; (4) $P Q+$ DDS: daily pretreatment with oral DDS $(0.5 \mathrm{mg} / \mathrm{kg}$ or 2 $\mathrm{mg} / \mathrm{kg}$ ) for 1 week, and then treatment with $P Q(10 \mathrm{mg} / \mathrm{kg})$ once for 5 days; and (5) DDS: daily treatment with oral DDS $(2 \mathrm{mg} / \mathrm{kg}$ ) for the entire experimental period. The lungs of the experimental animals were dissected and analyzed to determine the effects of DDS. All of the animal studies were approved by the Animal Experimentation Committee of Seoul National University.

\section{Extraction procedure and HPLC condition for paraquat analysis}

A Sep-Pak $C_{18}$ cartridge extraction procedure for $P Q$ in tissues reported by Fuke et al. (1992) was used. The lung tissues were ground with a homogenizer. To the homogenate, $5 \mathrm{ml}$ of $10 \%$ trichloroacetic acid solution (TCA) were added with vortex mixing. This was subjected to centrifuge at $2000 \times \mathrm{g}$ for $10 \mathrm{~min}$. The supernatant was adjusted to approximately $\mathrm{pH} 10$ with the addition of $2 \mathrm{M}$ sodium hydroxide solution and quickly applied to the Sep-Pak $C_{18}$ cartridge. The cartridge was successively washed with 5 $\mathrm{ml}$ of water, $3 \mathrm{ml}$ of methanol, and another $5 \mathrm{ml}$ of water. The substances were eluted with $4 \mathrm{ml}$ of $0.1 \mathrm{M}$ hydrochloric acid. The eluate was evaporated and dissolved in $100 \mu$ of a solution consisting of $10 \mathrm{mM}$ sodium octane sulfonate, $10 \mathrm{mM}$ triethylamine, and $0.5 \mathrm{M}$ potassium bromide (adjusted to $\mathrm{pH} 3.0$ with o-phosphoric acid). A 20- $\mu$ l aliquot of the solution was applied to the HPLC column.

The HPLC system consisted of a pump (G1311A, Agilent Technologies, Palo Alto, CA), UV detector (G1315A, Agilent Technologies), fluorescence detector (G1321A, Agilent Technologies), and auto-sample injector (G1329A, Agilent Technologies). The wavelength of the UV detector was set at $290 \mathrm{~nm}$ for the detection of PQ. The mobile phase consisted of $10 \mathrm{mM}$ sodium octane sulfonate, $10 \mathrm{mM}$ triethylamine, and $0.5 \mathrm{M}$ potassium bromide (adjusted to $\mathrm{pH} 3.0$ with o-phosphoric acid), and the flow rate was $1.0 \mathrm{ml} / \mathrm{min}$. 


\section{RT-PCR analysis}

Total RNA was prepared from mouse lung tissue using Trizol reagent (MRC), and the expression of ET-1, MIP- $1 \alpha$, TNF- $\alpha$, TGF- $\beta$, NOX2, NOX4, and $\beta$-actin mRNA was determined by RT-PCR, using a Biometra T Gradient PCR machine (Biometra, Goettingen, Germany). The following specific primers were used: ET-1, 5'-CTCTTCTGACCCCT TTGCAG-3' (forward) and 5'-GGTGAGCGCACTGACATC TA-3' (reverse); MIP-1 $\alpha, 5$ '-CACCCTCTGTCACCTGCTCA ACATC-3' (forward) and 5'-GGTTCCTCGCTGCCTCCAAG ACTCT-3' (reverse); TNF- $\alpha, 5$ '-CAGCCTCTTCTCATTCCT GCTTGTG-3' (forward) and 5'-CTGGAAGACTCCTCCCA GGTATAT-3' (reverse); TGF- $\beta, 5^{\prime}$-CGGGGCGACCTGGGC ACCATCCATGAC-3' (forward) and 5'-CTGCTCCACCTTG GGCTTGCGACCCAC-3' (reverse); NOX2, 5'-GCTGGGAT CACAGGAATTGT-3' (forward) and 5'-GGTGATGACCACC TTTTGCT-3' (reverse); NOX4, 5'-CCAGAATGAGGATCCC AGAA-3' (forward) and 5'-AAAACCCTCGAGGCAAAGAT-3' (reverse); GR, 5'-TCAAAGGCGTCTATGCTGTG-3' (forward) and 5'-GGTGACCAGCTCCTCTGAAG-3' (reverse); and $\beta$-actin, 5'-GGCGGACTATGACTTAGTTG-3' (forward) and 5'-AAACAACAATGTGCAATCAA-3' (reverse). The PCR products were separated by electrophoresis in $1.2 \%$ agarose gels, and the mRNA levels were quantified using Scion Image software (Scion, Frederick, MD). Target gene expression was normalized to the $\beta$-actin signal.

\section{Western blot analysis}

Lung tissues were removed from DDS- and PQ-treated mice, rinsed in ice-cold saline to remove excess blood, weighed, and finely minced. Tissue samples were homogenized twice for $20 \mathrm{~s}$ at $5,500 \mathrm{rpm}$ in RIPA lysis buffer (50 $\mathrm{mM}$ Tris- $\mathrm{HCl}, \mathrm{pH} 8.0,150 \mathrm{mM} \mathrm{NaCl}, 10 \%$ glycerol, $1 \% \mathrm{NP}$ $40,0.5 \%$ sodium deoxycholate, $0.1 \%$ SDS, $0.42 \% \mathrm{NaF}$ ) containing protease inhibitors ( $1 \mathrm{mM}$ phenylmethylsulfonyl fluoride, $1 \mathrm{mM} \mathrm{Na}_{3} \mathrm{VO}_{4}, 1 \%$ protease inhibitor cocktail; Sigma) using glass beads and a Precellys 24 homogenizer. The homogenates were clarified by centrifugation at $12,000 \times$ $g$ for 20 min. Following protein quantification using BCA protein assay reagent (Pierce, Rockford, IL), lysate samples were boiled in sample buffer $(50 \mathrm{mM}$ Tris- $\mathrm{HCl}, \mathrm{pH} 6.8$, $2 \%$ SDS, 0.14 M 2-mercaptoethanol, 10\% glycerol, 0.001\% bromophenol blue), separated by electrophoresis, and transferred to nitrocellulose membranes. The membranes were incubated with antibodies against PCKpan-p, PCK $\alpha$ $\beta-p, P K C \delta-p, P K C \mu-p, M M P-9$, MnSOD, GR, Prdx1, GST $\pi$, and $\beta$-actin. Bound primary antibody was detected using horseradish peroxidase-conjugated secondary antibody (Zymed, South San Francisco, CA) and ECL reagent (Pierce), followed by exposure to autoradiographic film. Signal intensity was determined using an LAS-3000 Image Reader (Fujifilm, Tokyo, Japan).

\section{Mouse lung fibroblast culture and dihydroethidium assay for superoxide anion monitoring using fluorescence microscope}

Whole lungs were removed from the mice, placed in Dulbecco's PBS (DPBS), minced into 2- to 3-mm pieces, and then incubated with $0.25 \%$ trypsin and $1 \mathrm{mM}$ EDTA at $37^{\circ} \mathrm{C}$ for $1 \mathrm{~h}$. The resulting cell suspensions were filtered through a 70- $\mu$ m nylon cell strainer (Corning-Costar, Acton, $M A)$, washed, and maintained in 100-mm dishes containing DMEM supplemented with $10 \%$ fetal bovine serum and antibiotics, at $37^{\circ} \mathrm{C}$ in a humidified $5 \% \mathrm{CO}_{2}$ atmosphere.

Intracellular superoxide anion levels were measured by dihydroethidium (DHE) assay; superoxide anion oxidizes DHE to oxoethidium, which is fluorescent. Primary mouse lung fibroblasts grown on coated $35-\mathrm{mm}$ dishes were pretreated with $20 \mu \mathrm{M}$ DDS for $3 \mathrm{~h}$ or with $5 \mu \mathrm{M}$ Gö6983 for 30 min and then treated with $250 \mu \mathrm{M} \mathrm{PQ}$ for $30 \mathrm{~min}$, followed by incubation with $5 \mu \mathrm{M}$ DHE for $15 \mathrm{~min}$ at $37^{\circ} \mathrm{C}$ in the dark. After two rinses in DPBS, fluorescence was visualized under an LSM 510 META fluorescence microscope (Carl Zeiss, Oberkochen, Germany).

\section{Dihydroethidium assay by HPLC analysis}

The sample preparation and HPLC analysis procedure for DHE was followed the method reported by Zhao et al. (2005a). The cells were lysed in a $0.25 \mathrm{ml}$ lysis buffer (DPBS with $0.1 \%$ Triton $\mathrm{X}-100, \mathrm{pH} 7.4$ ). Then, $10 \mu$ of lysis solution was used for measuring the protein concentration. The fluorescent dyes were extracted by adding $0.5 \mathrm{ml}$ of 1-butanol. This mixture was vortexed for $1 \mathrm{~min}$ and placed in a microfuge. The butanol phase was separated and evaporated to dryness, and then resuspended in $100 \mu \mathrm{l}$ of Milli $Q$ water before HPLC injection.

The DHE, $\mathrm{Et}^{+}$, and the $2-\mathrm{OH}-\mathrm{Et}^{+}$were separated on an HPLC system equipped with fluorescence and UV detectors. The mobile phase was $\mathrm{H}_{2} \mathrm{O} / \mathrm{CH}_{3} \mathrm{CN}$. The stationary phase was a $\mathrm{C}_{18}$ reverse-phase column. Fluorescence detection at $510 \mathrm{~nm}$ (excitation) and $595 \mathrm{~nm}$ (emission) was used to monitor these compounds. Typically, a $50 \mu$ sample was injected into the HPLC system (HP 1100, Agilent Technologies) with the $\mathrm{C}_{18}$ column equilibrated with $10 \% \mathrm{CH}_{3} \mathrm{CN}$ in $0.1 \%$ trifluoroacetic acid. $\mathrm{DHE}, \mathrm{Et}^{+}$, and the $2-\mathrm{OH}-\mathrm{Et}^{+}$ (DHE/O2 ${ }^{-}$-derived oxidation product) were separated by a linear increase in the $\mathrm{CH}_{3} \mathrm{CN}$ concentration from 10 to $70 \%$ in $46 \mathrm{~min}$ at a flow rate of $0.5 \mathrm{ml} / \mathrm{min}$. The elution was monitored by a variable UV detector at 210 and $350 \mathrm{~nm}$ and a fluorescence detector with excitation and emission at 510 and $595 \mathrm{~nm}$, respectively.

\section{TBARS assay}

As a measure of lipid peroxidation in mouse lung tissue, the level of thiobarbituric acid (TBA)-reactive substances (TBARS), a group of low-molecular-weight lipid peroxidation products consisting largely of malondialdehyde (MDA), was determined according to the method of Ohkawa et al (1979). This method has been criticized, because in this system, there are a large number of non-lipid oxidation products that also react with TBA to form colored species. An aliquot of lung tissue was mixed with $0.8 \%$ TBA in acetic acid ( $\mathrm{pH} \mathrm{3.4)} \mathrm{and} \mathrm{8.1 \%} \mathrm{SDS,} \mathrm{and} \mathrm{heated} \mathrm{in} \mathrm{boiling} \mathrm{wa-}$ ter for $30 \mathrm{~min}$. The absorbance of the product was measured at $532 \mathrm{~nm}$. TBARS are expressed as $\mu \mathrm{M} \mathrm{MDA} / \mathrm{mg}$ protein. 


\section{Statistical analysis}

All results are expressed as the mean \pm SD. Continuous variables were compared using Student's $t$-test or analysis of variance (ANOVA) followed by the Tukey test. All analyses were performed using SPSS software (ver. 15.0; SPSS, Chicago, IL). A value of $P<0.05$ indicated statistical significance.

\section{Acknowledgements}

This study has been supported by the grants from the National Research Foundation (2010-0029150), and also supported by the Seoul National University Brain Fusion Program Research Grant, Research Program of Cancer and Aging from KOSEF and KRIBB Research Institute Program, and the SNU BK21 Program from Ministry of Education, Science and Technology to Cho SC, Son YH and Lee SJ and from the Health Fellowship Foundation to Cho SC. We thank the Seoul branch of Korea Basic Science Institute (KBSI) for HPLC analysis experiments.

\section{References}

Anderson R, Theron AJ, Ras GJ. Regulation by the antioxidants ascorbate, cysteine, and dapsone of the increased extracellular and intracellular generation of reactive oxidants by activated phagocytes from cigarette smokers. Am Rev Respir Dis 1987;135:1027-32

Autor AP. Reduction of paraquat toxicity by superoxide dismutase. Life Sci 1974;14:1309-19

Bhaiya P, Roychowdhury S, Vyas PM, Doll MA, Hein DW, Svensson CK. Bioactivation, protein haptenation, and toxicity of sulfamethoxazole and dapsone in normal human dermal fibroblasts. Toxicol Appl Pharmacol 2006;215: 158-67

Bonneh-Barkay D, Reaney SH, Langston WJ, Di Monte DA. Redox cycling of the herbicide paraquat in microglial cultures. Brain Res Mol Brain Res 2005;134:52-6

Bradshaw TP, McMillan DC, Crouch RK, Jollow DJ. Formation of free radicals and protein mixed disulfides in rat red cells exposed to dapsone hydroxylamine. Free Radic Biol Med 1997;22:1183-93

Brandes RP, Kreuzer J. Vascular NADPH oxidases: molecular mechanisms of activation. Cardiovasc Res 2005;65:16-27

Bus JS, Aust SD, Gibson JE. Paraquat toxicity: proposed mechanism of action involving lipid peroxidation. Environ Health Perspect 1976;16:139-46

Castello PR, Drechsel DA, Patel M. Mitochondria are a major source of paraquat-induced reactive oxygen species production in the brain. J Biol Chem 2007;282:14186-93

Cho SC, Rhim JH, Son YH, Lee SJ, Park SC. Suppression of ROS generation by 4,4'-diaminodiphenylsulfone in non-phagocytic human diploid fibroblasts. Exp Mol Med 2010a;42:223-32

Cho SC, Park MC, Keam B, Choi JM, Cho Y, Hyun S, Park SC, Lee J. DDS, 4,4'-diaminodiphenylsulfone, extends organismic lifespan. Proc Natl Acad Sci USA 2010b;107: 19326-31

Cooper JA, Zitnik RJ, Matthay RA. Mechanisms of druginduced pulmonary disease. Annu Rev Med 1988;39: 395-404

Day BJ, Patel M, Calavetta L, Chang LY, Stamler JS. A mechanism of paraquat toxicity involving nitric oxide synthase. Proc Natl Acad Sci USA 1999;96:12760-5

De luliis GN, Wingate JK, Koppers AJ, McLaughlin EA, Aitken RJ. Definitive evidence for the nonmitochondrial production of superoxide anion by human spermatozoa. $\mathrm{J}$ Clin Endocrinol Metab 2006;91:1968-75

Du HY, Olivo M, Tan BK, Bay BH. Photoactivation of hypericin down-regulates glutathione S-transferase activity in nasopharyngeal cancer cells. Cancer Lett 2004;207:175-81

Fuke C, Ameno K, Shirakawa Y, Ameno S, Kiriu T, Shinohara T. Simultaneous determination of paraquat and diquat in biological materials using high performance liquid chromatography and its application to poisoned patients (in Japanese with English abstract). Jpn J Toxicol 1992;5:387-93

Hecker L, Vittal R, Jones T, Jagirdar R, Luckhardt TR, Horowitz JC, Pennathur S, Martinezl FJ, Thannickall VJ. NADPH oxidase- 4 mediates myofibroblast activation and fibrogenic responses to lung injury. Nat Med 2009;15: 1077-81

Hocher B, Schwarz A, Fagan KA, Thone-Reineke C, El-Hag $\mathrm{K}$, Kusserow $\mathrm{H}$, Elitok $\mathrm{S}$, Bauer $\mathrm{C}$, Neumayer $\mathrm{HH}$, Rodman DM, Theuring F. Pulmonary fibrosis and chronic lung inflammation in ET-1 transgenic mice. Am J Respir Cell Mol Biol 2000;23:19-26

Hoffer E, Avidor I, Benjaminov O, Shenker L, Tabak A, Tamir $A$, Merzbach D, Taitelman U. N-acetylcysteine delays the infiltration of inflammatory cells into the lungs of paraquatintoxicated rats. Toxicol Appl Pharmacol 1993;120:8-12

Ishida $\mathrm{Y}$, Takayasu T, Kimura A, Hayashi T, Kakimoto N Miyashita T, Kondo T. Gene expression of cytokines and growth factors in the lungs after paraquat administration in mice. Leg Med (Tokyo) 2006;8:102-9

Kaehler J, Sill B, Koester R, Mittmann C, Orzechowski HD, Muenzel T, Meinertz T. Endothelin-1 mRNA and protein in vascular wall cells is increased by reactive oxygen species. Clin Sci (Lond) 2002;103:176S-178S

Kähler J, Mendel S, Weckmuller J, Orzechowski HD, Mittmann C, Koster R, Paul M, Meinertza T, Münzela T. Oxidative stress increases synthesis of big endothelin-1 by activation of the endothelin-1 promoter. J Mol Cell Cardiol 2000;32:1429-37

Kim HR, Park BK, Oh YM, Lee YS, Lee DS, Kim HK, Kim JY, Shim TS, Lee SD. Green tea extract inhibits paraquatinduced pulmonary fibrosis by suppression of oxidative stress and endothelin-I expression. Lung 2006;184:287-95

Martinet $\mathrm{Y}$, Menard O, Vaillant P, Vignaud JM, Martinet N. Cytokines in human lung fibrosis. Arch Toxicol Suppl 1996; 18:127-39

Martyn KD, Frederick LM, von Loehneysen K, Dinauer MC, Knaus UG. Functional analysis of Nox4 reveals unique characteristics compared to other NADPH oxidases. Cell 


\section{Signal 2006;8:69-82}

Miller RL, Sun GY, Sun AY. Cytotoxicity of paraquat in microglial cells: Involvement of PKCdelta- and ERK1/2dependent NADPH oxidase. Brain Res 2007;1167:129-39

Nerlich AG, Nerlich ML, Langer I, Demling RH. Release of amino-terminal procollagen peptides in paraquat-induced acute pulmonary fibrosis. Exp Mol Pathol 1984;40:311-9

Niwa Y, Sakane T, Miyachi Y. Dissociation of the inhibitory effect of dapsone on the generation of oxygen intermediates--in comparison with that of colchicine and various scavengers. Biochem Pharmacol 1984;33:2355-60

Ohkawa H, Ohishi N, Yagi K. Assay for lipid peroxides in animal tissues by thiobarbituric acid reaction. Anal Biochem 1979;95:351-8

Piette WW, Taylor S, Pariser D, Jarratt M, Sheth P, Wilson D. Hematologic safety of dapsone gel, $5 \%$, for topical treatment of acne vulgaris. Arch Dermatol 2008;144:1564-70

Reilly TP, Woster PM, Svensson CK. Methemoglobin formation by hydroxylamine metabolites of sulfamethoxazole and dapsone: implications for differences in adverse drug reactions. J Pharmacol Exp Ther 1999;288:951-9

Rennecke J, Johannes FJ, Richter KH, Kittstein W, Marks F, Gschwendt M. Immunological demonstration of protein kinase $\mathrm{C} \mathrm{mu}$ in murine tissues and various cell lines. Differential recognition of phosphorylated forms and lack of down-regulation upon 12-O-tetradecanoylphorphol-13-acetate treatment of cells. Eur J Biochem 1996;242:428-32

Rossary A, Arab K, Steghens JP. Polyunsaturated fatty acids modulate NOX 4 anion superoxide production in human fibroblasts. Biochem J 2007;406:77-83

Satomi Y, Tsuchiya W, Mihara K, Ota M, Kasahara Y, Akahori F. Gene expression analysis of the lung following paraquat administration in rats using DNA microarray. J Toxicol Sci 2004;29:91-100

Serrander L, Cartier L, Bedard K, Banfi B, Lardy B, Plastre O, Sienkiewicz A, Forro L, Schlegel W, Krause KH. NOX4 activity is determined by mRNA levels and reveals a unique pattern of ROS generation. Biochem J 2007;406:105-14

Shimokawa I, Park SC, Mori N, Hwang ES. Japan-Korea joint seminar: Asian aging core for longevity 2008 in Nagasaki -toward the establishment of an Asian aging research and education center-September 4th to 6th, 2008 at Huis ten Bosch, Nagasaki, Japan. Mech Ageing Dev 2009;130:198-201

Skillrud DM, Martin WJ. Paraquat-induced injury of type II alveolar cells. An in vitro model of oxidant injury. Am Rev Respir Dis 1984;129:995-9

Smith RE, Strieter RM, Zhang K, Phan SH, Standiford TJ, Lukacs NW, Kunkel SL. A role for C-C chemokines in fibrotic lung disease. J Leukoc Biol 1995;57:782-7

Sturrock A, Cahill B, Norman K, Huecksteadt TP, Hill K, Sanders K, Karwande SV, Stringham JC, Bull DA, Gleich M, Kennedy TP, Hoidal JR. Transforming growth factor-beta1 induces Nox4 NAD(P)H oxidase and reactive oxygen species-dependent proliferation in human pulmonary artery smooth muscle cells. Am J Physiol Lung Cell Mol Physiol 2006;290:L661-L673
Suda T, Suzuki Y, Matsui T, Inoue T, Niide O, Yoshimaru T, Suzuki H, Ra C, Ochiai T. Dapsone suppresses human neutrophil superoxide production and elastase release in a calcium-dependent manner. Br J Dermatol 2005;152:887-95

Talior I, Tennenbaum T, Kuroki T, Eldar-Finkelman $\mathrm{H}$. PKC-delta-dependent activation of oxidative stress in adipocytes of obese and insulin-resistant mice: role for NADPH oxidase. Am J Physiol Endocrinol Metab 2005;288: E405-11

Thabut G, El-Benna J, Samb A, Corda S, Megret J, Leseche G, Vicaut E, Aubier M, Boczkowski J. Tumor necrosis factor-alpha increases airway smooth muscle oxidants production through a NADPH oxidase-like system to enhance myosin light chain phosphorylation and contractility. J Biol Chem 2002;277:22814-21

Tomita M. Comparison of one-electron reduction activity against the bipyridylium herbicides, paraquat and diquat, in microsomal and mitochondrial fractions of liver, lung and kidney (in vitro). Biochem Pharmacol 1991;42:303-9

Tomita M, Okuyama T, Katsuyama H, Miura Y, Nishimura Y, Hidaka K, Otsuki T, Ishikawa T. Mouse model of paraquatpoisoned lungs and its gene expression profile. Toxicology 2007;231:200-9

Tsukamoto M, Tampo Y, Sawada M, Yonaha M. Paraquatinduced membrane dysfunction in pulmonary microvascular endothelial cells. Pharmacol Toxicol 2000;86:102-9

Tsunobuchi $H$, Ishisaki $A$, Imamura $T$. Expressions of inhibitory Smads, Smad6 and Smad7, are differentially regulated by TPA in human lung fibroblast cells. Biochem Biophys Res Commun 2004;316:712-9

van der Vliet A. NADPH oxidases in lung biology and pathology: host defense enzymes, and more. Free Radic Biol Med 2008;44:938-55

Veggi LM, Pretto L, Ochoa EJ, Catania VA, Luquita MG, Taborda DR, Sánchez Pozzi EJ, Ikushiro S, Coleman MD, Roma MG, Mottino AD. Dapsone induces oxidative stress and impairs antioxidant defenses in rat liver. Life Sci 2008;83:155-63

Venkatesan N. Pulmonary protective effects of curcumin against paraquat toxicity. Life Sci 2000;66:PL21-8

Wolf R, Matz H, Orion E, Tuzun B, Tuzun Y. Dapsone. Dermatol Online J 2002;8:2

Wood LG, Garg ML, Simpson JL, Mori TA, Croft KD, Wark PA, Gibson PG. Induced sputum 8-isoprostane concentrations in inflammatory airway diseases. Am J Respir Crit Care Med 2005;171:426-30

Xu H, Goettsch C, Xia N, Horke S, Morawietz H, Förstermann $\mathrm{U}, \mathrm{Li} \mathrm{H}$. Differential roles of PKCalpha and PKCepsilon in controlling the gene expression of Nox4 in human endothelial cells. Free Radic Biol Med 2008;44:1656-67

Zhao H, Joseph J, Fales HM, Sokoloski EA, Levine RL, Vasquez-Vivar J, Kalyanaraman B. Detection and characterization of the product of hydroethidine and intracellular superoxide by HPLC and limitations of fluorescence. Proc Natl Acad Sci USA 2005a;102:5727-32

Zhao X, Xu B, Bhattacharjee A, Oldfield CM, Wientjes FB, 
Feldman GM, Cathcart MK. Protein kinase Cdelta regulates p67phox phosphorylation in human monocytes. J Leukoc Biol 2005b;77:414-20

Zone J. Dermatitis herpetiformis. Curr Probl Dermatol
1991;3:6-41

Zuidema J, Hilbers-Modderman ES, Merkus FW. Clinical pharmacokinetics of dapsone. Clin Pharmacokinet 1986;11: 299-315 